\title{
EVALUATING RESOURCE EFFICIENCY FOR PRINTED CIRCUIT BOARD WASTE SORTING AND TRANSFER PLANT USING MATERIAL FLOW COST ACCOUNTING
}

\author{
Supanisara Wanwong ${ }^{1,2}, *$ Suphaphat Kwonpongsagoon ${ }^{1,2}$ and Kanokwan Kingphadung ${ }^{3}$ \\ ${ }^{1}$ Department of Sanitary Engineering, Faculty of Public Health, Mahidol University, Thailand; \\ ${ }^{2}$ Center of Excellence on Environmental Health and Toxicology (EHT), Thailand; \\ ${ }^{3}$ Department of Food Technology, Faculty of Engineering and Industrial Technology, Silpakorn University, \\ Thailand
}

*Corresponding Author, Received: 30 Nov. 2021, Revised: 8 Dec. 2021, Accepted: 26 Dec. 2021

\begin{abstract}
This paper aimed to evaluate the resource efficiency of a printed circuit board waste (PCBW) sorting and transfer plant by identifying quantities of production loss and their associated true costs using the Material Flow Cost Accounting (MFCA) technique. The results of this study are based on data gathered in 2019. The 5 types of waste material input transferred directly to the production system are, namely wastewater sludge, PCB border, PCB scrap, drilling PCB and punching PCB powder. The findings showed that positive and negative product costs were identified as $94 \%$ and $6 \%$ of the total cost, respectively. The greatest portion of the negative product cost resulting from system cost (SC) was 50\% of the negative product cost or 3\% of the total cost. Punching PCB waste was found to be the highest loss cost, about 54\%. Regarding waste management loss cost (WC), all waste handling and disposal costs were attributable to two material losses, namely punching PCB residue and PCB scrap. Based on the overall results of this study, the resource efficiency of the PCBW sorting and transfer plant in terms of the ratio of the recoverable precious metal - copper $(\mathrm{Cu})$ could be quantified as 0.94 which was in accordance with the positive product cost of MFCA technique.
\end{abstract}

Keywords: MFCA, PCB waste, Sorting and transfer, Resource, Efficiency

\section{INTRODUCTION}

Electronic waste (e-waste) or waste from electrical and electronic equipment (WEEE) is one of the fastest-growing waste streams in the world both in terms of volume and growth rate. In 2016, the report of the global e-waste monitor stated that one Thai citizen produces $7.4 \mathrm{~kg}$ of e-waste per year and increased to $9.2 \mathrm{~kg}$ per year in 2019, making Thailand the fourth largest e-waste generator among ASEAN countries [1,2]. In addition to domestic generation, it has been reported that Thailand received imports of various kinds of electronic waste scraps from other developed countries, e.g., the US, China, Japan, Belgium, France, and the UK, around 64,437 tons in 2017 and 52,221 tons during the first half of 2018 [3]. As a result, the increasing volume of e-waste has become a serious concern in this country.

Printed circuit board (PCB) waste is an essential component of all electrical and electronic equipment (EEE), used to connect electronic devices on the circuit board, making the devices connected and able to work as designed. About 3\% by weight of the WEEE are printed circuit board (PCB) consisting of around 30\% metals and 70\% non-metallic materials [4]-[6]. In general, the major economic driving force for recycling printed circuit board waste (PCBW) is the high value of metallic materials, i.e., gold $(\mathrm{Au})$, palladium $(\mathrm{Pd})$, silver $(\mathrm{Ag})$, and copper $(\mathrm{Cu})$. In Thailand, only copper is feasibly recovered from wastes of PCB production and post-consumer waste PCB [7].

According to Thailand's 20 years' national strategy, the government has set a national goal to handle and reduce all waste types properly by 2037 [8], which makes the recycling business serve an important role. In 2018, a total of 3,102 recycling businesses were newly registered, with a tendency to continually rise, and around $57 \%$ (or 1,761 factories) were e-waste recycling businesses $[9,10]$. Among these e-waste recyclers, about $70 \%$ were registered as waste collectors and transporters, which were classified as Factory type 105, and the rest were e-waste recyclers, classified as Factory type 106 - both factory types prescribed in the Thailand Ministerial Regulation No.2 B.E. 2535 (1992) issued under the Factory Act B.E. 2535 (1992). In addition, Krung Thai Bank Research Center [11] reported that the overall recycling market increased around $5.7 \%$ yearly or $1.2 \%$ of the total GDP, with a value of 1.7 billion Thai baht (THB) in 2019, and estimated to be 2.24 billion THB in 2024. It appears that the increasing trend of recycling businesses generally corresponds to the high waste generation of the country. 
Material flow cost accounting (MFCA) (ISO standard 14051) is one of the environmental management tools, developed in Germany in the late 1990s and widely applied in the domestic industry of Japan by the Asian Productivity Organization (APO). MFCA helps increase the transparency of the material flow of production processes, which is a key to successful problem solving and industrial process improvement. The MFCA technique can identify quantities of production loss in physical units and identify quantities of true costs associated with production loss in monetary units [12]. By focusing on both the costs of products and the costs associated with materials losses, the ultimate purpose of MFCA is beneficial to identify opportunities to reduce materials use and losses, to improve the efficiency of materials and energy use, and to reduce adverse environmental impacts [13]. To date, MFCA has been widely applied in an extensive variety of industries including food, automotive, metal, chemicals, and textile industries [14-24]. Among these MFCA applications, the method has also been extended to combine other techniques such as Lean, life cycle assessment and costing (LCA/LCC), enterprise resource planning systems, and causeeffect diagram [14,15,20,23].

\section{RESEARCH SIGNIFICANCE}

This study constitutes the first time to evaluate the resource efficiency of an e-waste recycling business in Thailand, focusing on a printed circuit board waste sorting and transfer plant, by identifying quantities of production loss and their associated true costs using the Material Flow Cost Accounting (MFCA) technique. Ultimately, the results will highlight improvable hotspots where waste management costs and inefficiency of processes occur and imply reduced environmental impacts (air pollution, water pollution, health problems, etc.).

\section{METHODS}

\subsection{System Boundary and Data Collection}

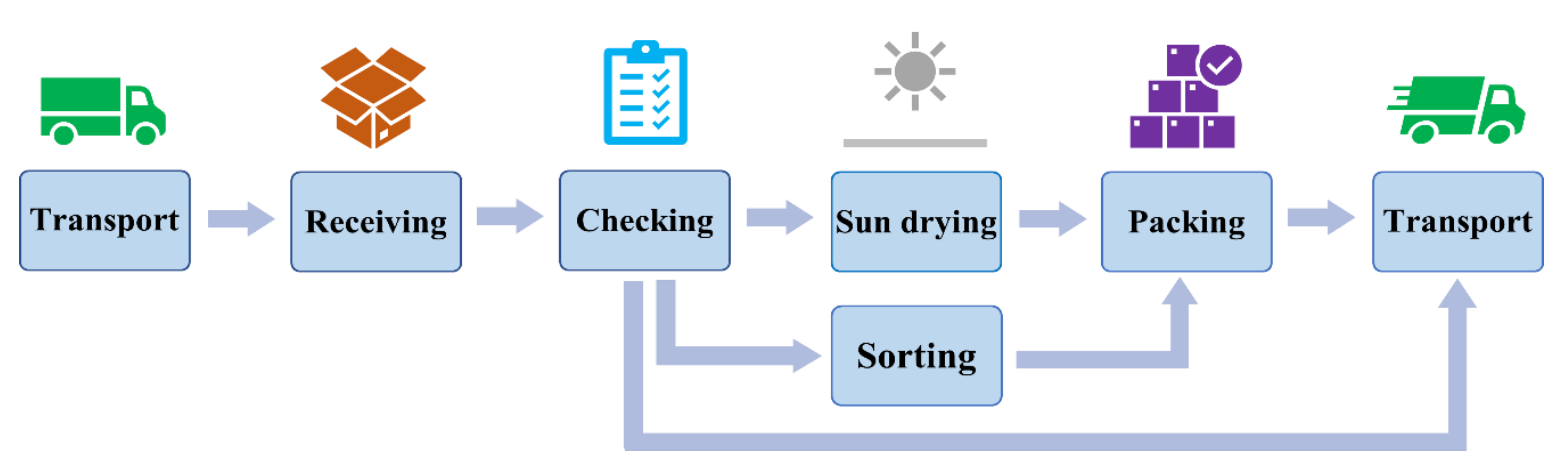

The study was conducted in a small to mediumsized (SME) printed circuit board waste (PCBW) sorting and transfer plant located in Suphanburi Province, Thailand. The plant is classified as Factory type 105, a factory engaged in businesses related to sorting and/ or landfill facility for wastes with characteristics and qualifications as prescribed in Thailand Ministerial Regulation no. 2 B.E. 2535 (1992) issued under the regulations in the Factory Act B.E. 2535 (1992). As can be seen in Fig. 1, the system boundary starts by transporting various waste types to the plant, followed by waste receiving, checking, sorting, sun drying, packing process, and transporting waste products out to another recycling plant. It covered seven activities/processes of the PCBW sorting and transfer plant, including transportation.

The data used in this study were primary data collected from the plant, representing one year in 2019. These collected data included inputs, outputs, received, other materials/energy/ fuel used, waste rejected, and costs associated with various processes across the target plant as described in Fig.1.

\subsection{Creation of Material and Copper Flow Model}

According to the MFCA, a flow diagram of the production process or material was firstly created, showing input material, product, and waste of each subprocess and the entire process of the system boundary. Concerning the PCBW plant in this study, attention was drawn to the high-value substances embedded in waste PCBs. As mentioned above, because $\mathrm{Cu}$ is one of the substances that is feasible to recover in the next stage of the recycling facility, the model of $\mathrm{Cu}$ flow was then created here along with the material flow model. The flow diagrams can trace all input materials and substance $(\mathrm{Cu})$ that flowed through production processes and measure products and material/substance loss (waste) in $\mathrm{kg}$. and cost information, for example, amount of waste

Fig.1 System boundary of the study 
The physical flow results for both material and $\mathrm{Cu}$ are based on the law of mass conservation. It could be explained that the mass of a material or substance never changes. Thus, all input materials and substances $(\mathrm{Cu})$ equal the amount of output products (positive products) added to that of generated waste (negative products). The equation represents the identification of material/substance balance and measures products and material/substance loss (waste) in physical units using the following Eq. (1):

$$
\frac{d \operatorname{Mar}(i)}{d t}=\sum(\text { inputs })-\sum(\text { outputs })
$$

where $\operatorname{Mar}(\mathrm{i})=$ mass changed with respect to time (one year in this study).

Each material or substance $(\mathrm{Cu})$ that goes in and out of the production process flow should be balanced. Thus, the target product in the MFCA analysis, the material/substance input and output need to be confirmed while comparing the quantities of material inputs to outputs and to identify any data gaps. The missing materials/substances or other data gaps could lead to identifying missing points resulting in areas of improvement [12].

\subsection{Calculation of MFCA-Based Costs}

The material balance of inputs and outputs obtained from the material model in physical units (or weight) is linked to monetary units, by allocating costs to all products and material losses. The costs are measured in Thai Baht (THB). Under MFCA, four types of costs are generally considered quantifiable, namely, material costs, (MC) energy costs (EC), system costs (SC), and waste management costs (WC) [12]. Details of each cost analyzed in this study are defined as described below.

- Material cost: costs for raw materials and subsidiary materials, e.g., packaging, canvas

- $\quad$ Energy cost: costs for energy sources such as electricity and automotive fuel (for trucks and forklifts)

- $\quad$ System cost: salary and wage incurred by labor in transportation

- Waste management cost: costs for handling material losses

\section{RESULTS AND DISCUSSION}

\subsection{Material and Copper Flows}

In 2019, the five input materials of waste PCB collected and transported to the PCBW sorting and transfer plant included wastewater sludge, $\mathrm{PCB}$ border, PCB scrap, drilling PCB powder, and punching PCB powder as shown in Fig.2. Each type of waste input has different characteristics and properties as follows: wastewater sludge is a sludge with an initial moisture content of $59 \%$ (wet weight basis) obtained from the wastewater treatment plant of PCB manufacture where wastewater generated from the cleaning process of drilled holes; PCB border and scrap are waste PCBs collected from the PCB cutting process; and drilling and punching PCB are PCB powder residues, generated from both drilling and punching processes. All five waste inputs contain different amounts of valuable metals, particularly $\mathrm{Cu}$. It was estimated that the $\mathrm{Cu}$ content in drilling PCB residue, wastewater sludge (dry weight), and PCB border and scrap is around 30 to $40 \%, 10$ to $30 \%$, and 3 to $5 \%$, respectively. For the punching $\mathrm{PCB}$ residue, too little $\mathrm{Cu}$ content was reported and infeasible to recover further, and is normally sent to another waste recycling plant for treatment.
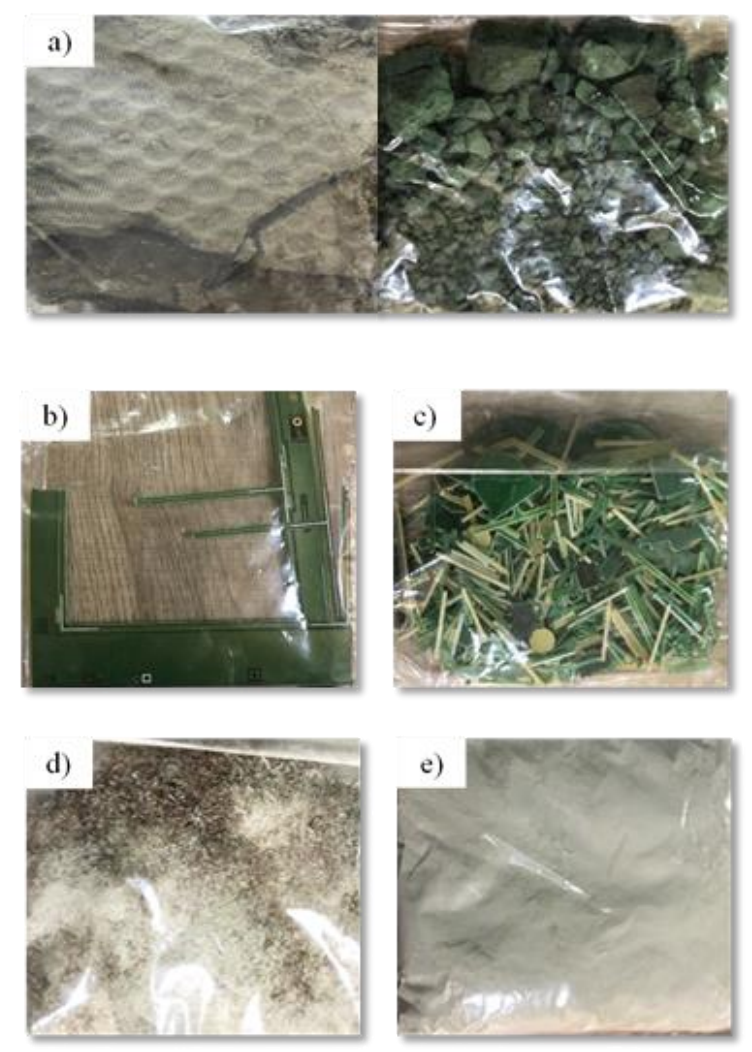

Fig.2 Various types of PCB waste input: a) wastewater sludge (wet and dry); b) PCB border; c) PCB scrap, d) drilling PCB powder; and e) punching PCB powder. 


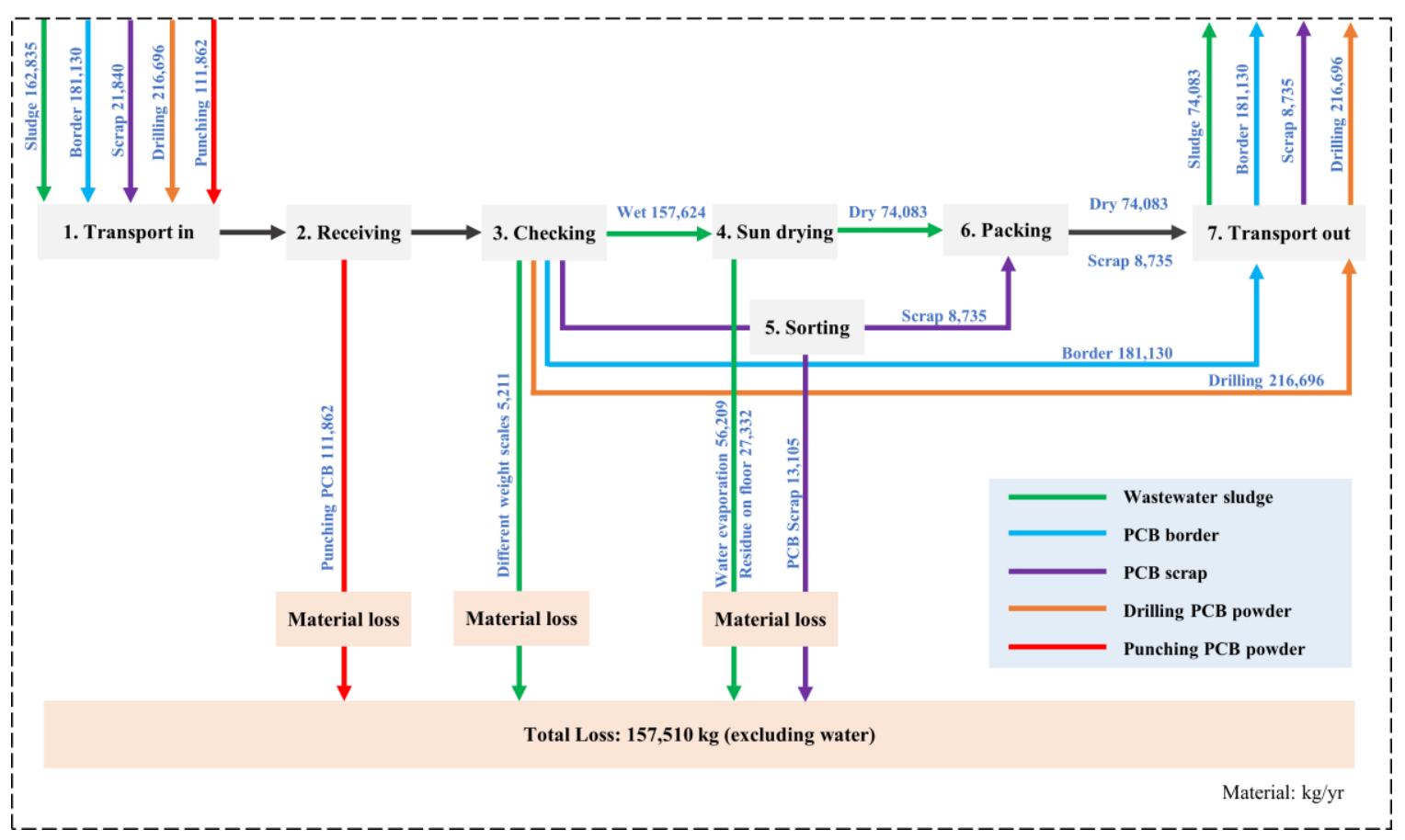

Fig.3 The result of material flows for a PCBW sorting and transfer plant in Thailand

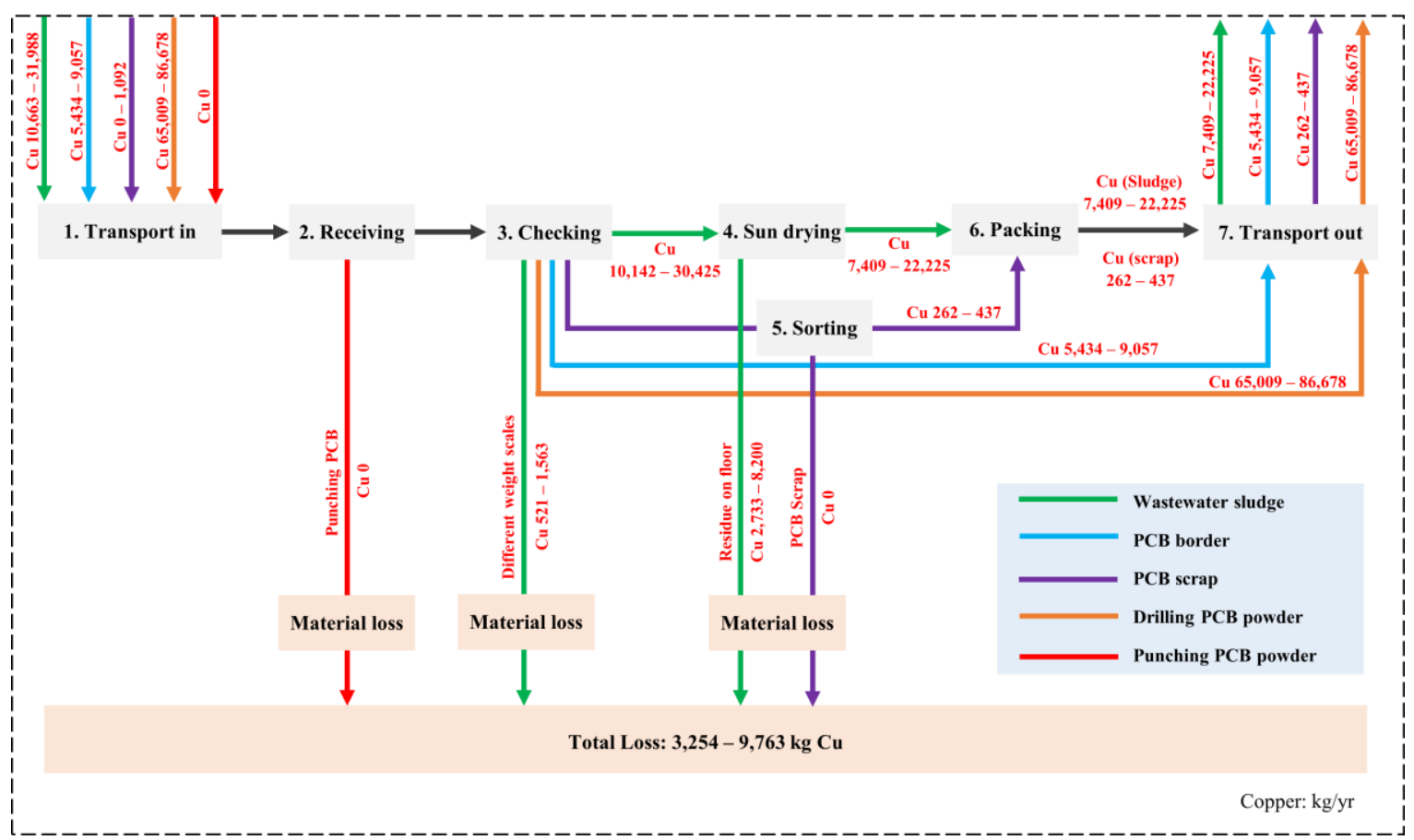

Fig.4 The result of copper flows for a PCBW sorting and transfer plant in Thailand

In 2019, PCBW input materials were picked up from different PCB manufacturing sources a total of 64 times, and transported to the PCBW sorting and transfer plant, while PCBW products were transported out from the PCBW sorting and transfer plant a total of 61 times to a recycling plant located in another province. The analyzed process for material and copper flows of the PCBW sorting and transfer plant can be separated into seven units: transporting in, receiving, checking, sun drying, sorting, packing, and transporting out, as illustrated in Fig.3 and Fig.4.

In Fig.3, all material flow results were estimated by excluding the amount of water in wastewater sludge. Based on the material flow model, total waste inputs (initial waste PCBs) 
transported to this plant was $694,363 \mathrm{~kg}$ yearly which ultimately yielded (positive products) $480,644 \mathrm{~kg}$ yearly or $69 \%$ of all waste inputs), and generated material loss (waste PCB or negative products) totaled $157,510 \mathrm{~kg}$ yearly or $23 \%$ of all waste inputs. As presented in Fig.3, in terms of material flow, the results indicated that the highest material loss occurred during the receiving process $(111,862 \mathrm{~kg}$ yearly), followed by sun drying, sorting, and checking processes. Nevertheless, when considering the $\mathrm{Cu}$ flow model in Fig.4, the total loss of $\mathrm{Cu}$ was 3,254 to $9,763 \mathrm{~kg}$ yearly depending on the $\mathrm{Cu}$ content from waste PCB inputs, with the highest $\mathrm{Cu}$ loss occurring during sun drying activity. Among those material losses, punching PCB powder was identified as the most negative product, around $71 \%$ derived from the receiving process. Although $\mathrm{Cu}$ content was hardly found in punching PCB residues as mentioned above, the PCBW sorting and transfer plant had to handle and transfer this residue for further disposal as a complimentary waste because of the request by PCB manufacturers. The second and third material losses were wastewater sludge, which can be blown away to the air and leftover on a concrete floor during and after the open-air sun drying process as shown in Fig.5, and PCB scraps from sorting activity about $17 \%$ and $8 \%$ of the total loss, respectively. The loss of these PCB scraps was about $60 \%$ of the initial scrap inputs and assumed to be $\mathrm{Cu}$-free scraps. These scraps were separated manually using simply invented sorting equipment. The last material loss was calculated based on the difference in weighting scales used between the waste generator (using a digital scale) and the PCBW sorting and transfer plant (using a mechanical or iron cast balance beam scale), around $3 \%$ of the total loss.

Concerning evaluating the conventional resource efficiency of the PCBW sorting and transfer plant in terms of the ratio of material outputs to inputs, it could be estimated at 0.69 (excluding water). Regarding this estimation, the resource efficiency was not likely in this case and underestimated for the plant operation. In the case of waste PCB, the prioritization of waste recovery focused on precious metals. Thus, the resource efficiency here should look at the ratio of the weight of the final precious metal $-\mathrm{Cu}$ embedded in the sorted PCB wastes (outputs) to the initial $\mathrm{Cu}$ contained in waste PCB inputs, rather than the conventional ratio of material outputs to inputs as reported above in Fig 3. Therefore, the resource efficiency of the PCBW sorting and transfer plant by considering $\mathrm{Cu}$ flow results (Fig.4) could be quantified as high as 0.94 instead of 0.69 from the results of Fig.3.

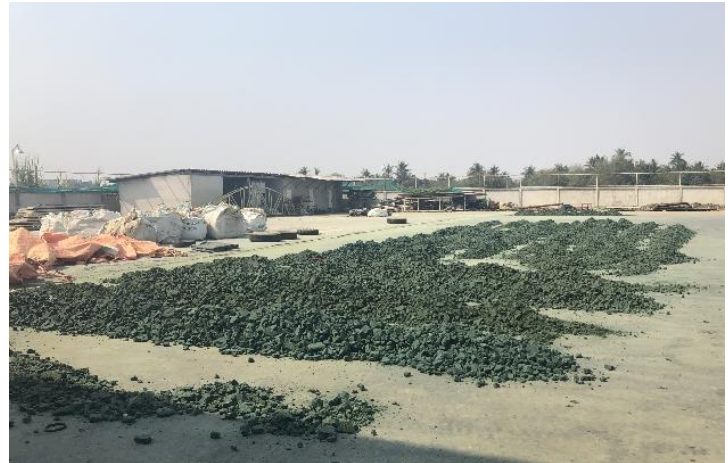

Fig.5 The current open-air sun drying process

\subsection{Material Flow Cost Accounting}

As a result of detailed cost allocation following the mass balance concept applied to the material flow model above, a material flow cost matrix for five different PCB wastes is presented in Table 1, and a summary of the cost ratio of total positive and negative products is depicted separately in Fig.6.

In Table 1, $82 \%$ of the overall manufacturing costs come from two waste types - PCB border and drilling PCB which were allocated mostly to material costs. When focusing on the negative product cost, the major portion results from system costs (SC) about $50 \%$ or $3 \%$ of the total costs. These system loss costs, mainly labor and transportation costs, were generated from punching PCB residue accounting for $26 \%$ of the negative product cost, followed by PCB scrap (16\%) and wastewater sludge $(8 \%)$. Waste management loss cost was generated from two material losses, namely, punching PCB residue (17\% of the total negative cost) and PCB scrap (3\%). Among these five different waste types, punching $\mathrm{PCB}$ residue contributed the highest negative product cost, approximately 54\% comprising system (26\%), waste management (17\%), and energy loss costs (11\%).

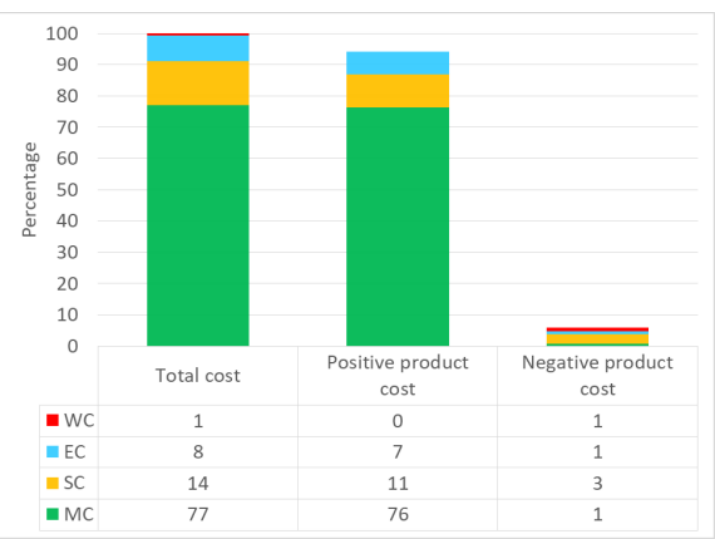

Fig.6 Summary of cost ratio in the MFCA 
Table 1 Material flow cost matrix for five PCB waste types

\begin{tabular}{|c|c|c|c|c|c|c|}
\hline \multirow{2}{*}{ Cost type } & \multirow{2}{*}{$\begin{array}{l}\text { Total Cost } \\
\text { THB (\%) }\end{array}$} & \multicolumn{5}{|c|}{ PCB waste type in THB (\%) } \\
\hline & & Sludge & Border & Scrap & Drilling & Punching \\
\hline Material Cost & $6,022,381(77)$ & $307,253(4)$ & $2,898,080(37)$ & $\mathbf{0}(\mathbf{0})$ & $2,817,048(36)$ & $\mathbf{0}(\mathbf{0})$ \\
\hline Positive product & $5,960,976(76)$ & $245,848(3)$ & $2,898,080(37)$ & $0(0)$ & $2,817,048(36)$ & $0(0)$ \\
\hline Negative product & $61,405(1)$ & $61,405(1)$ & $0(0)$ & $0(0)$ & $0(0)$ & $0(0)$ \\
\hline System Cost & $1,052,322(14)$ & $282,619(4)$ & $174,219(2)$ & $270,858(4)$ & $174,658(2)$ & $149,968(2)$ \\
\hline Positive product & $823,683(11)$ & $245,012(3.5)$ & $174,219(2)$ & $197,051(3)$ & $174,658(2)$ & $32,743(0.5)$ \\
\hline Negative product & $228,639(3)$ & $37,607(0.5)$ & $0(0)$ & $73,807(1)$ & $0(0)$ & $117,225(1.5)$ \\
\hline Energy Cost & $646,576(8)$ & $140,363(2)$ & $220,227(3)$ & $24,651(0)$ & $180,591(2)$ & $80,744(1)$ \\
\hline Positive product & $569,544(7)$ & $120,870(2)$ & $220,227(3)$ & $16,356(0)$ & $180,591(2)$ & $31,500(0)$ \\
\hline Negative product & $77,032(1)$ & $19,493(0)$ & $0(0)$ & $8,295(0)$ & $0(0)$ & $49,244(1)$ \\
\hline Waste management Cost & $91,377(1)$ & $\mathbf{0}(\mathbf{0})$ & $\mathbf{0}(\mathbf{0})$ & $13,074(0)$ & $\mathbf{0}(\mathbf{0})$ & $78,303(1)$ \\
\hline Positive product & $0(0)$ & $0(0)$ & $0(0)$ & $0(0)$ & $0(0)$ & $0(0)$ \\
\hline Negative product & $91,377(1)$ & $0(0)$ & $0(0)$ & $13,074(0)$ & $0(0)$ & $78,303(1)$ \\
\hline Total Cost THB (\%) & $7,812,656(100)$ & $730,235(10)$ & $3,292,526(42)$ & $308,583(4)$ & 3,172,297 (40) & $309,015(4)$ \\
\hline
\end{tabular}

Note: all figures are shown in this table based on one year.

As shown in Fig.6, based on the MFCA, the overall cost can be summarized in positive and negative product costs of $94 \%$ and $6 \%$, respectively. Using the MFCA technique, the resource efficiency of the plant was 0.94 , agreeing with the estimation in the previous section of this study. In determining resource efficiency, the estimation based on a recoverable precious metal $(\mathrm{Cu})$ and its flow model is compatible with the MFCA technique as described above (both calculated at 0.94). As the results of this study indicated, two processes were analyzed as high $\mathrm{Cu}$ losses, particularly $\mathrm{Cu}$ from wastewater sludge, at sun drying and weight checking processes that should be the focus for further improvement. A recommendation regarding the sun drying process was that improved cost savings and reduced air pollution could be achieved by switching from drying on an open-air floor to a closed drying system such as a greenhouse solar dryer (see Fig.7). For the inefficiency of the weight checking process, changing to using a digital weighing scale was recommended for this plant. In terms of material loss costs, although punching PCB residue clearly produces significant costs for this manufacturing process, reducing such costs was deemed impossible because of the complimentary waste requested for handling by the PCB manufacturers.

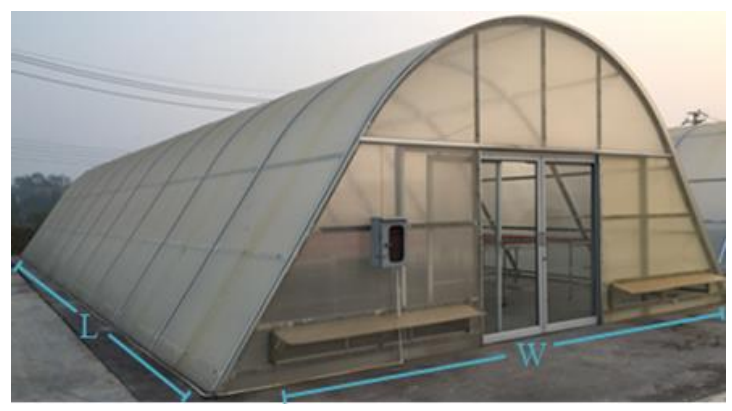

Fig.7 A greenhouse solar dryer [25]

\section{CONCLUSION}

To address losses and cost-saving potentials of the PCBW plant, not just materials of the production process should be traced, but also precious metals $(\mathrm{Cu})$ present in waste PCBs. Evidently, the results of this study highlight 
improvable hotspots where waste management costs and inefficiency of processes occurred. It could be concluded that the greatest portion of the negative product cost resulting from SC was $50 \%$ of the negative product costs (or $3 \%$ of the total cost). Regarding WC, all waste handling and disposal costs were attributable to two material losses, namely, punching PCB residue (17\% of the total negative costs) and PCB scrap (3\%). Punching PCB waste was the main contributor to negative product costs. Overall, the resource efficiency of the plant could be evaluated at 0.94 . All these helpful results are expected to lead to improved and reduced environmental and health impacts of the plant.

\section{ACKNOWLEDGMENTS}

This research work was financially supported by the Center of Excellence on Environmental Health and Toxicology (EHT), Science \& Technology Postgraduate Education and Research Development Office (PERDO), Ministry of Education, Thailand.

\section{REFERENCES}

[1] Baldé C.P., Forti V., Gray V., Kuehr R. and Stegmann P., The Global E-waste Monitor 2017, United Nations University (UNU), International Telecommunication Union (ITU) \& International Solid Waste Association (ISWA), 2017, pp.107.

[2] Forti V., Baldé C.P., Kuehr R. and Bel G., The Global E-waste Monitor 2020: Quantities, flows, and the circular economy potential. United Nations University (UNU)/United Nations Institute for Training and Research (UNITAR) - co-hosted SCYCLE Programme, International Telecommunication Union (ITU) \& International Solid Waste Association (ISWA), 2020, pp.114.

[3] Thai Customs Department, Situation and Measures on the Import-Export of Electronic Scrap and Plastic Scrap [Internet]. 2018 [cited 2020 April 4]. Available from https://www. customs.go.th.

[4] Kanchanapiya P., E-waste: Printed circuit board scrap management technology, National Science and Technology Development Agency, 2011.

[5] Sohaili J., Muniyandi S. and Suhaila S., A review on printed circuit boards waste recycling technologies and reuse of recovered nonmetallic materials. International Journal of Scientific \& Engineering Research, 2012, Vol. 3(2), pp. 1-7.

[6] Coombs C. F. Jr., Printed circuit handbook, 6th ed. McGraw-Hill, 2018.

[7] Tesanan S., Kwonpongsagoon S. and Kanchanapiya P., Solidification/stabilization of nonvaluable residue from waste printed circuit board assembly. International Journal of GEOMATE, 2016, Vol. 11, Issue 24, pp. 23072313.

[8] Strategy and Planning Division Office of the Permanent Secretary, Twenty-Year National Strategic Plan (2017-2036). Bangkok. Thailand: National Library of Thailand, 2017.

[9] Prachachat News, Recycling business over a hundred billion in revenue [Internet]. 2018 [cited 2020 April 5]. Available from https://www.prachachat .net/columns/news205219

[10] Naewna News, 'Department of Industrial Works' controls tightening E-waste recycling plants [Internet]. 2018 [cited 2020 April 5]. Available from https://www.naewna.com/business/341446

[11] Krung Thai Bank Research Center, Marketing Strategy Department, Krung Thai points out the waste recycling business via a digital platform to increase the potential to tackle environmental challenges [Internet]. 2020 [cited 2020 May 11]. Available from https://krungthai.com/th/krung thaiupdate/news-detail/484.

[12] Tachikawa H., Manual on Material Flow Cost Accounting ISO 14051. Asian Productivity Organization, 2014.

[13] Nakajima M., The New Management Accounting Field Established by Material Flow Cost Accounting (MFCA). Kansai University Review of Business and Commerce, Vol. 8, 2006, pp. 1-22.

[14] Chattinnawat W., Teeratanasombut M. and Kammoon C., Development of analysis method of material flow cost accounting using lean technique in food production: A case study of Universal Food Public (UFC) Co., Ltd., KKU Engineering Journal, Vol. 42(2), 2015, pp. 155-172.

[15] Chaiwan W., Boonmee C. and Kasemset C., Waste Reduction in Meat Processing Industry: the application of MFCA (ISO 14051). Toward Sustainable Operations of Supply Chain and Logistics Systems, 2015, pp. 183-193.

[16] Fakoya M.B. and Margaretha van der Poll H., Integrating ERP and MFCA systems for improved waste-reduction decisions in a brewery in South Africa. Journal of Cleaner Production, Vol. 40, 2013, pp. 136-140.

[17] Kurdve M., Shahbazi S., Wendin M., Bengtsson C. and Wiktorsson M., Waste flow mapping to improve sustainability of waste management: a case study approach. Journal of Cleaner Production, Vol. 98, 2014, pp. 304315.

[18]Chang S., Material Flow Cost Accounting System for Decision Making: The Case of Taiwan SME in the Metal Processing Industry. 
Asian Journal of Finance \& Accounting, Vol. 7(1), 2015, pp. 117-134.

[19]Behnami A., Benis K.Z., Shakerkhatibi M., Fatehifar E., Derafshi S. and Chavoshbashi M.M., Integrating data reconciliation into material flow cost accounting: the case of a petrochemical wastewater treatment plant. Journal of Cleaner Production, Vol. 218, 2019, pp. 616-628.

[20] Kasemset C., Chernsuporncha J. and Pala-ud W., Application of MFCA in waste reduction: a case study on a small textile factory in Thailand. Journal of Cleaner Production, Vol. 108, 2014, pp. 1342-1351.

[21] Schaltegger S., Bennett M., Burritt R.L. and Jasch C., Environmental Management Accounting for Cleaner Production. Springer, Vol. 5, 2008.

[22] Nakano K. and Hirao M., Collaborative activity with business partners for improvement of product environmental performance using LCA. Journal of Cleaner
Production, Vol. 19, pp. 1189-1197.

[23] Bierer A., Götze U., Meynerts L. and Sygulla R., Integrating life cycle costing and life cycle assessment using extended material flow cost accounting. Journal of Cleaner Production, Vol. 108, 2014, pp. 1289-1301.

[24] Wan Y.K., Ng R.T.L., Ng D.K.S. and Tan R.R., Material flow cost accounting (MFCA)-based approach for prioritization of waste recovery. Journal of Cleaner Production, Vol. 107, 2015, pp. 602-614.

[25] Krungkaew S., Kingphadung K., Kwonpongsagoon S., and Mahayothee B., Costs and benefits of using parabolic greenhouse solar dryers for dried herb products in Thailand. International Journal of GEOMATE, 2020, Vol. 18, Issue 67, pp. 96101.

Copyright (C) Int. J. of GEOMATE All rights reserved, including making copies unless permission is obtained from the copyright proprietors. 